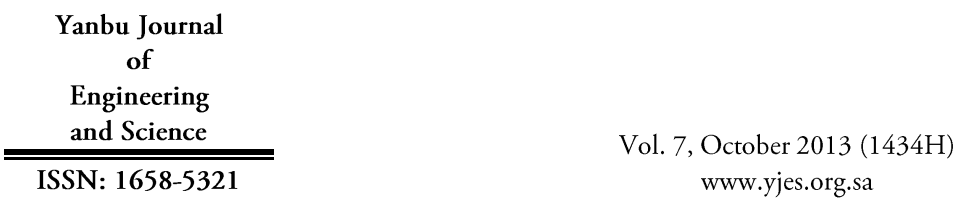

\title{
HEAT DISSIPATION ANALYSIS OF A FIN WITH HEXAGONAL PERFORATIONS OF ITS ONE SIDE PARALLEL TO THE FIN BASE
}

\author{
Abdullah H. M. AlEssa \\ Northern Borders University, Department of Mechanical Engineering, Engineering Faculty-Arar, \\ Kingdom of Saudi Arabia \\ email:abdd104@yahoo.com \\ On leave from: AlBalqa Applied University, AlHusn University College, AlHusn, Irbid, Jordan
}

\begin{abstract}
Finite element method (FEM) is among important numerical techniques used in thermal engineering analyses. Usually elements are sub-divided uniformly in FEM to obtain temperature distribution in a fin or plate. In this paper heat transfer dissipation from a horizontal rectangular fin embedded with hexagonal perforations is computed numerically using one dimensional finite element technique. The orientation of the hexagonal perforations makes two sides of it parallel to the base and tip of the fin. The body of the fin is discretized into the sufficient finite elements. The number of these elements can be altered as required according to the automatic mesh generation. The heat dissipation of the perforated fin is computed and compared with that of the solid one of the same dimensions and same thermal properties. The comparison refers to acceptable results and heat dissipation enhancement due to certain perforation.
\end{abstract}

Keywords: Finite Element, Perforated Fin, Heat Dissipation, Heat transfer enhancement.

\section{INTRODUCTION}

Compact heat exchangers are designed in configurations that have a large heat transfer surface area per unit of volume. The large area per unit of volume can be attained by attaching extended surfaces (fins). The fins of the plate-fin surfaces are frequently cut into segments or otherwise interrupted in various ways. These modifications are for increasing the heat transfer coefficient and sometimes to increase heat transfer surface area $[1,2]$. It is worth mentioning that a large number of studies have been conducted to find the optimum shape of fins (rectangular, hexagonal, pin, wavy, serrated, and slotted). Some of these studies are based on splitting a certain dimension of the fin in an optimal way provided that the total volume of the fin material is fixed. Others have introduced some shape modifications by cutting some material from the fin to make cavities, holes, slots, grooves, or perforations through the fin body $[2,3,4,5]$. Due to the high demand for lightweight, compact, and economical fins, the optimization of fin size is of great importance [6]. Therefore, fins must be designed to achieve maximum heat removal with minimum material expenditure taking into account, however, the ease of manufacturing of the fin shape. One popular heat transfer augmentation technique involves the use of rough surfaces of different configurations. The surface roughness aims at promoting surface turbulence that is intended mainly to increase the heat transfer coefficient rather than the surface area [1]. Several other researchers reported a similar trend for interrupted (e.g. perforated) fins attributing the improvement to the restarting of the 
thermal boundary layer after each interruption indicating that the increase in convection coefficient is more than enough to offset lost area, if there is any $[2,6,7]$. The fin industry has been engaged in continuous research to reduce the fin size, weight and cost. The reduction in fin size and cost is achieved by the enhancement of heat transfer carried out by the fins. This enhancement can be accomplished by the following means:

1- Increasing the ratio of the heat transfer surface area of the fin to its volume

2- Manufacturing fins from materials having high thermal conductivity

3- Increasing the heat transfer coefficient between the fin and its surroundings

Perforated plates or perforated fins represent an example of surface interruption [3]. They are widely used for multiple-plate heat exchangers, film cooling (e.g., of turbine blades), and solar collector applications [8].

An experimental study was conducted to investigate the dissipation heat transfer by natural convection in a rectangular fin plate with circular perforations as heat sinks. In this study it is found that, the heat transfer rate and the coefficient of heat transfer increased with an increased number of perforations [9].

A three-dimensional numerical computational study is made for turbulent fluid flow and convective heat transfer around an array of rectangular solid and new design of perforated fins with different numbers and two various sizes of perforations. In this study, the fin efficiency of perforated fins is determined and compared with the equivalent solid fin. Results show that new perforated fins have higher total heat transfer and considerable weight reduction in comparison with solid fins[10]. Th is study aims mainly to introduce a numerical finite element general solution of the problem of heat transfer from a fin with hexagonal surface perforations. This solution is restricted to the fact that the Biot Number in lateral and longitudinal directions less than 0.01 .

\section{ASSUMPTION FOR ANALYSIS}

The study of most heat transfer references shows that the classical analyses of fins employ a one-dimensional heat conduction model. The Biot number is very small (less than 0.01 ), therefore a one-dimensional solution can be considered $[11,12]$. The analysis and results reported in this study are based on the following assumptions:

1. Steady-state, one-dimensional analysis

2. The fin material is homogeneous and isotropic with constant thermal conductivity

3. No heat sources/sinks in the fin body

4. Uniform base and ambient temperatures

5. The surface heat transfer coefficients are uniform

\section{HEAT TRANSFER ANALYSIS}

The perforated fin with hexagonal perforations which is considered in this study is shown in Fig. 1. Fig. 2 shows the symmetry part considered for heat transfer analysis (shown hatched). For this part the transverse Biot number in or along the direction of $\mathrm{z}$ axis $\left(\mathrm{Bi}_{\mathrm{Z}}\right)$ can be calculated by:

$\mathrm{Bi}_{\mathrm{z}}=\mathrm{h}_{\mathrm{pc}} \cdot \mathrm{t} / 2 \mathrm{k}$

and the transverse Biot number in or along the direction of $\mathrm{y}$-axis $\left(\mathrm{Bi}_{\mathrm{y}}\right)$ can be calculated by:

$$
\left.\mathrm{Bi}_{\mathrm{y}}=\mathrm{h}_{\mathrm{ps} .} . \mathrm{S}_{\mathrm{y}}+\mathrm{b}(0.5+\operatorname{Sin}(30))\right) / \mathrm{k}
$$

As the values of $\left(\mathrm{Bi}_{\mathrm{z}}\right)$ and $\left(\mathrm{Bi}_{\mathrm{y}}\right)$ are less than 0.01 , then the heat transfer in $(\mathrm{z})$ and $(\mathrm{y})$ directions can be assumed lumped and a onedimensional solution can be considered. 
If the values of $\left(\mathrm{Bi}_{\mathrm{z}}\right)$ and $\left(\mathrm{Bi}_{\mathrm{y}}\right)$ are greater than 0.01 , then the heat transfer solution must be in two or three dimensions. In this study the parameters of the perforated fin are taken as they lead to values of $\left(\mathrm{Bi}_{\mathrm{Z}}\right)$ and $\left(\mathrm{Bi}_{\mathrm{y}}\right)$ smaller than 0.01 . Based on the above assumptions, the energy equation of the fin along with the boundary conditions and according to figures 1,2 and 3 may be stated as below $[13,14,15]$

$k \frac{d^{2} T}{d x^{2}}=0$

The associated boundary conditions are

1 - At the base surface $(\mathrm{x}=0)$

$\mathrm{T}=\mathrm{T}_{\mathrm{b}}$

2- At the perforated surfaces and the tip of the fin

$\mathrm{kA}_{\mathrm{e}} \frac{\mathrm{dT}}{\mathrm{dx}} l_{\mathrm{x}}+\mathrm{h}_{\mathrm{ps}} \mathrm{A}_{\mathrm{ps}}\left(\mathrm{T}-\mathrm{T}_{\infty}\right)+\mathrm{h}_{\mathrm{pc}} \mathrm{A}_{\mathrm{pc}}\left(\mathrm{T}-\mathrm{T}_{\infty}\right)+\mathrm{h}_{\mathrm{t}} \mathrm{A}_{\mathrm{t}}\left(\mathrm{T}_{\mathrm{t}}-\mathrm{T}_{\infty}\right)=0$

In this study, the energy equation shown in (1) is solved numerically utilizing the one dimensional finite-element technique. The corresponding variational statement as it is described in [13] has the following form:

$$
\begin{aligned}
I_{n}= & \frac{1}{2} \iiint_{V e} k\left(\frac{d T}{d x}\right)^{2} d V+\frac{1}{2} \iint_{p s} h_{p s}\left(T-T_{\infty}\right)^{2} d A_{p s}+ \\
& \frac{1}{2} \iint h_{p c}\left(T-T_{\infty}\right)^{2} d A_{p c}+\iint_{A_{t}} h_{t}\left(T_{t}-T_{\infty}\right) T d A_{t}
\end{aligned}
$$

The variational approach in matrix notation [13] is used in formulating the algebraic equations of the problem of this perforated fin. The formulation of these equations can be found in details in [13]. The perforated fin elements and body discretization of the symmetry part are shown in figures 2 and 3 . As shown in Figure 3, surrounding each semi-

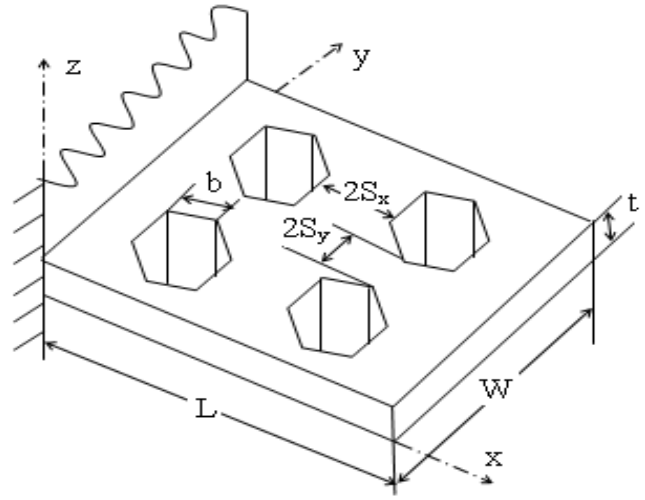

Fig. 1. The fin with hexagonal perforations

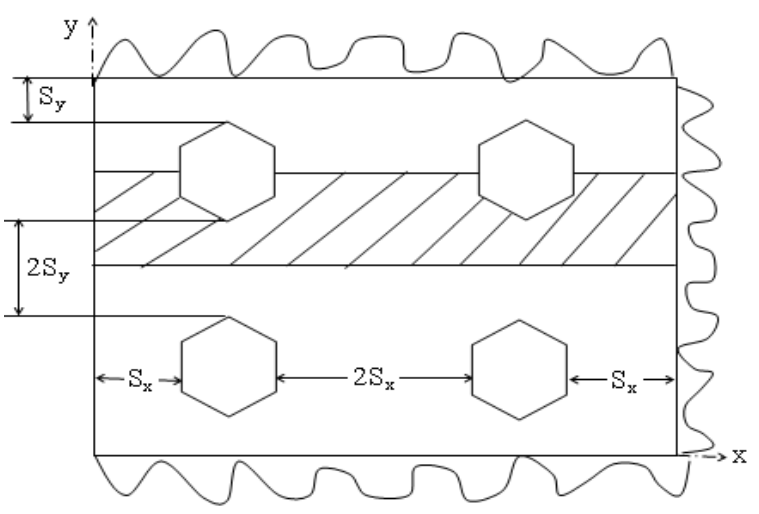

Fig. 2. The symmetrical hatched part used in the mathematical formulation of the perforated fin

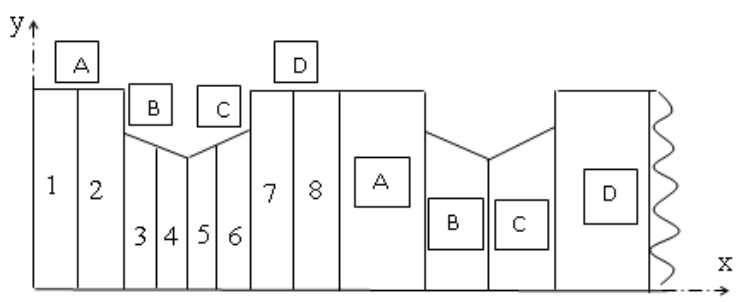

Fig. 3. Expanded symmetrical part with the four regions A, B, C and $\mathrm{D}$ considered in the mathematical formulation $(1,2,3, \ldots$. numbers of the linear finite elements).

perforation there are four regions labeled A, $B, C$ and D. These regions which repeat themselves along $\mathrm{x}$ direction around each perforation are considered in formulating the discretization mesh and finite element equations. The regions $\mathrm{A}$ and $\mathrm{D}$ are divided into $\mathrm{N}_{\mathrm{f}}$ elements each, while the regions $\mathrm{B}$ and $\mathrm{C}$ are divided into $\mathrm{N}_{\mathrm{t}}$ elements each. The perforated fin length and width can be computed by the following equations: 


$$
\begin{aligned}
& \mathrm{L}=2 \cdot \mathrm{N}_{\mathrm{x}}\left(\mathrm{S}_{\mathrm{x}}+\mathrm{b} \cdot \operatorname{Cos}\left(30^{\circ}\right)\right) \\
& \mathrm{W}=\mathrm{N}_{\mathrm{y}}\left(2 \cdot \mathrm{S}_{\mathrm{y}}+2 \cdot \mathrm{b} \cdot \operatorname{Sin}\left(30^{\circ}\right)+\mathrm{b} / 2\right)
\end{aligned}
$$

To compare the perforated fin with the solid one, their dimensions (length, width, and thickness) are considered the same. The solid and perforated fin heat transfer surfaces can be computed by the following equations:

$$
\begin{aligned}
A_{s f} & =P . L+W \cdot t \\
A_{p f} & =A_{s f}+N_{x} N_{y}\left(A_{p c}-2 A_{c}\right) \\
& =A_{s f}+6 \cdot N_{x} N_{y}\left(b \cdot t-b^{2} \operatorname{Sin}\left(60^{\circ}\right)\right)
\end{aligned}
$$

The total number of elements $\mathrm{N}_{\mathrm{e}}$ and the total number of nodes $\mathrm{N}_{\mathrm{n}}$ are expressed as:

$$
\begin{aligned}
& \mathrm{N}_{\mathrm{e}}=\mathrm{N}_{\mathrm{x}}\left(2 \mathrm{~N}_{\mathrm{f}}+\mathrm{N}_{\mathrm{t}}\right) \\
& \mathrm{N}_{\mathrm{f}}=\operatorname{Int}\left(\mathrm{S}_{\mathrm{x}} / \mathrm{Le}\right) \\
& \mathrm{Nt}=\operatorname{Int}(\mathrm{b} * \operatorname{Cos}(30) / \mathrm{Le}) \\
& \mathrm{N}_{\mathrm{n}}=\mathrm{N}_{\mathrm{e}}+1
\end{aligned}
$$

The results of this solution are the perforated fin temperature distribution along its length direction ( $x$ coordinate). Once the temperature distribution along the perforated fin length is obtained, the heat dissipation rate from the perforated fin $\left(Q_{p f}\right)$ can be computed by one of the following three expressions:

1- The expression of heat dissipation that depends on the integration over all the perforated fin surfaces which can be converted into summation over all finite elements as shown here:

$$
\begin{aligned}
\mathrm{Q} 1= & 2 \mathrm{~N}_{\mathrm{y}} \cdot \sum_{\mathrm{I}=1}^{\mathrm{N}_{\mathrm{e}}}\left(\frac{\mathrm{T}_{\mathrm{I}}+\mathrm{T}_{\mathrm{I}+1}}{2}-\mathrm{T}_{\infty}\right)\left(\mathrm{h}_{\mathrm{ps}}\left(\frac{\mathrm{Pe}(\mathrm{I})+\mathrm{Pe}(\mathrm{I}+1)}{2}\right) \mathrm{Le}(\mathrm{I})+\mathrm{h}_{\mathrm{pc}} \mathrm{L}_{\mathrm{pc}}(\mathrm{I}) \cdot \mathrm{t}\right) \\
& +\mathrm{Q}_{\mathrm{t}}+\mathrm{Q}_{\mathrm{S}}
\end{aligned}
$$

Where $\mathrm{Q}_{\mathrm{t}}$ and $\mathrm{Q}_{\mathrm{s}}$ are the heat dissipation from the tip and the two sides of the perforated fin, and can be calculated by the following expressions:

$$
\begin{aligned}
& Q_{t}=A_{t} h_{t}\left(T_{t}-T_{\infty}\right) \\
& Q_{S}=2 \sum_{I=1}^{N}\left(\frac{T_{I}+T_{I+1}}{2}-T_{\infty}\right)\left(h_{s} \cdot \operatorname{Le}(I) \cdot t\right)
\end{aligned}
$$

2- The expression of heat dissipation that depends on Fourier's Law:

$$
\mathrm{Q} 2=-\mathrm{k} \cdot \mathrm{A} \cdot\left(\frac{\mathrm{dT}}{\mathrm{dx}}\right) \text { at } \mathrm{x}=0=-2 \mathrm{~N}_{\mathrm{y}} \mathrm{kt}\left(\mathrm{S}_{\mathrm{y}}+\mathrm{b} / 2\right)\left(\frac{\mathrm{dT}}{\mathrm{dx}}\right) \text { at } \mathrm{x}=0
$$

The first derivative of the temperature distribution at $(\mathrm{x}=0)$ can be approximated by using the two temperatures of the two nodes of the first finite element of the fin as shown in the following expression:

$\mathrm{Q} 2=2 \mathrm{~N}_{\mathrm{y}} \mathrm{k} \cdot \mathrm{t}\left(\mathrm{S}_{\mathrm{y}}+\mathrm{b} / 2\right) \frac{\mathrm{T}_{1}-\mathrm{T}_{2}}{\mathrm{Le}}$

3- The expression of heat dissipation that depends on the first equation of the algebraic equation system which can be expressed as:

$\mathrm{Q} 3=2 \mathrm{~N}_{\mathrm{y}}\left(\mathrm{GK}(1,1) \cdot \mathrm{T}_{1}+\mathrm{GK}(1,2) \mathrm{T}_{2}\right)$

Where $\operatorname{GK}(1,1)$ and $\operatorname{GK}(1,2)$ are the first and second constants of the first algebraic equation in the finite element solution.

The theoretical maximum heat dissipation of the fin is obtained when the temperature of the whole fin body equals the fin base temperature and it can be computed by the following expression:

$\mathrm{Q}_{\mathrm{pf}, \max }=\left(\mathrm{A}_{\mathrm{ps}} \cdot \mathrm{h}_{\mathrm{ps}}+\mathrm{N}_{\mathrm{x}} \cdot \mathrm{N}_{\mathrm{y}} \cdot \mathrm{A}_{\mathrm{pc}} \cdot \mathrm{h}_{\mathrm{pc}}+\mathrm{A}_{\mathrm{t}} \cdot \mathrm{h}_{\mathrm{t}}+\mathrm{A}_{\mathrm{s}} \cdot \mathrm{h}_{\mathrm{s}}\right)\left(\mathrm{T}_{\mathrm{b}}-\mathrm{T}_{\infty}\right)$

The fin efficiency is defined as the ratio of the heat transfer from the fin in its actual temperature distribution to its maximum heat transfer. Consequently, the fin efficiency is expressed as

$\eta_{\mathrm{pf}}=\mathrm{Q}_{\mathrm{pf}} / \mathrm{Q}_{\mathrm{pf}, \max }$ 
In order to compare performance of the perforated fin with that of the solid (nonperforated) one of the same dimensions, the following equations of the solid fin consider convection heat transfer from its tip as described in [14] are used.

$\mathrm{Q}_{\mathrm{sf}}=\mathrm{k} \cdot \mathrm{A} \cdot \mathrm{m}\left(\mathrm{T}_{\mathrm{b}}-\mathrm{T}_{\infty}\right) \frac{\operatorname{Sinh}(\mathrm{m} \cdot \mathrm{L})+\left(\mathrm{h}_{\mathrm{t}} /(\mathrm{m} \cdot \mathrm{k})\right) \operatorname{Cosh}(\mathrm{m} \cdot \mathrm{L})}{\operatorname{Cosh}(\mathrm{m} \cdot \mathrm{L})+\left(\mathrm{h}_{\mathrm{t}} /(\mathrm{m} \cdot \mathrm{k})\right) \operatorname{Sinh}(\mathrm{m} \cdot \mathrm{L})}$

where $\mathrm{m}$ is defined as

$\mathrm{m}=\sqrt{\frac{\mathrm{h} \cdot \mathrm{P}_{\mathrm{sf}}}{\mathrm{k} \cdot \mathrm{A}}}$

Where $\mathrm{Q}_{\mathrm{f}}$ is the heat dissipation rate of the solid fin [16].

The ratio of the heat dissipation of the perforated fin to that of the solid one (RQF) is introduced and given by:

$\mathrm{RQF}=\mathrm{Q}_{\mathrm{pf}} / \mathrm{Q}_{\mathrm{sf}}$

\section{RESULT AND DISCUSSION}

It is believed that comparing the perforated fin with its solid counterpart is the best means to evaluate the difference in heat transfer brought about by introducing the fin perforations. In the following analysis, verification, and discussion, and where there is a comparison between the two fins, it is assumed that both fins have the same dimensions $(\mathrm{L}=50, \mathrm{~W}=100 \mathrm{~mm}$ ), same thermal conductivity, same heat transfer coefficient for all surfaces of the perforated and solid fins $\left(h=h_{p c}=h_{p s}=h_{s}=h_{t}=20 \mathrm{~W} / \mathrm{m}^{2} .^{\circ} \mathrm{C}\right)$, and same base temperature $\left(\mathrm{T}_{\mathrm{b}}=100{ }^{\circ} \mathrm{C}\right)$ and ambient temperature $\left(\mathrm{T}_{\infty}=20^{\circ} \mathrm{C}\right)$. The longitudinal and lateral perforation spacing are $\left(S_{x}=S_{y}=1 \mathrm{~mm}\right)$. The other values are mentioned in their suitable places.

\subsection{Temperature Distribution OF THE PERFORATEd Fin}

The temperature distribution along the fin length has an important effect on the fin's performance. Higher fin temperatures can be obtained as the fin's thermal conduction resistance is decreased. The temperature distribution of the perforated fin $\left(\mathrm{T}_{\mathrm{pf}}\right)$ along the $\mathrm{x}$-coordinate is plotted in Fig. 4. From this figure it is obvious that the temperature distributions show non uniform curves caused by perforations which lead to varying area of cross sections along the fin's length and then lead to varying thermal resistance in the fin along the fin length. The effect of variation of cross sectional area of the perforated fin on thermal resistance decreases as the thermal conductivity increases so the curves become more uniform. To compare the temperature distribution of the perforated fin with that of the solid one, the temperature difference distribution of the solid fin and the perforated fin $\left(T_{s f}-T_{p f}\right)$ is plotted in Fig. 5. As shown in this figure it is obvious that the temperatures along the solid fin are higher than those of the perforated one in all cases. This is because the thermal conduction resistance of the perforated fin is always higher than that of the corresponding non-perforated one. As the thermal conductivity increases the difference $\left(\mathrm{T}_{\mathrm{sf}}-\mathrm{T}_{\mathrm{pf}}\right)$ decreases and it diminishes for very high thermal conductivities. That is, because as thermal conductivity approaches very high values, then the fin (solid or perforated) becomes almost isothermal with the base temperature $\left(\mathrm{T}_{\mathrm{b}}\right)$. Figures ( 4 and 5 ) show that the temperature difference (temperature drop) between the fin base and its tip increases as the hexagonal perforation dimension (b) is increased. This is because the thermal resistance of the perforated fin increases as (b) is increased. Consequently, from only a temperature distribution viewpoint, it would be recommended to use a perforation with dimensions as small as possible. Also it can be deduced from temperature distribution that fin temperatures increase as the fin thickness is increased. This is readily explained by the 
fact that the thermal resistance of the perforated fin decreases as the fin thickness is increased. Therefore, from the temperature distribution viewpoint, it is preferable to use as large as possible fin thickness. The temperature and temperature difference distributions shown in figures (4 and 5) indicate acceptable results as they are compared with those of the solid fin.

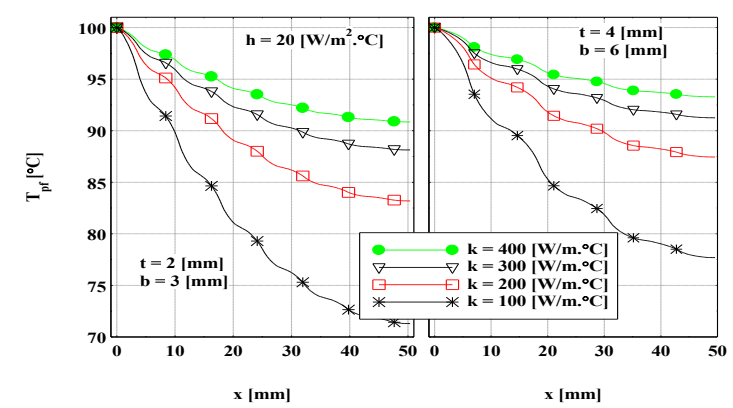

Fig.4. Temperature distribution of the perforated fin along its length $\left(S_{\mathrm{x}}=\mathrm{S}_{\mathrm{y}}=1 \mathrm{~mm}\right)$.

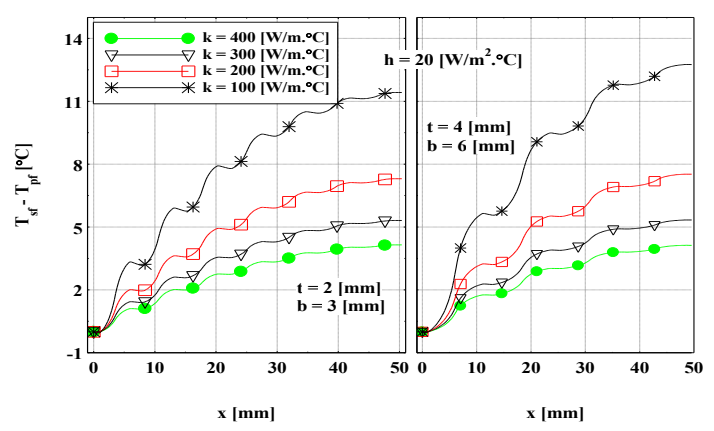

Fig.5. Temperature difference between that of the solid fin and that of the perforated one along its length $(S x=S y=1 \mathrm{~mm})$.

\subsection{HEAT DISSIPATION RATE OF THE PERforated Fin}

The heat dissipation rates $(\mathrm{Q} 1, \mathrm{Q} 2, \mathrm{Q} 3$ and $\mathrm{Q}_{\mathrm{pf} \text {,max }}$ ) of the perforated fin are plotted in terms of fin thermal conductivity with various hexagonal perforation dimension (b) and fin thickness as shown in Fig. 6. The results show that Q1 differs from the values of Q2, Q3. The value of $\mathrm{Q} 1$ seems more acceptable because it doesn't exceed the maximum value $\left(\mathrm{Q}_{\mathrm{pf}, \max }\right)$. The values of Q2 and Q3 seem unacceptable because they fluctuate around and exceed the maximum value $\left(\mathrm{Q}_{\mathrm{pf}, \max }\right)$. The reason for wrong values of Q2 and Q3 is that these values as they are computed by equations $(15,16)$ in which the calculations depend on the temperatures $\left(T_{1}\right.$ and $\left.T_{2}\right)$ at the two sides of the first finite element. This means that any error in $\left(T_{1}\right.$ and $\left.T_{2}\right)$ will significantly appear on the values of Q2, Q3 . The value Q1 depends on all temperatures $T_{1}, T_{2}, T_{3}, \ldots . . T_{n}$ of the finite elements. This means that the errors in the finite element temperatures along the fin length will diminish each others. To check the stability and convergence of the perforated fin heat dissipations (Q1, Q2, Q3) according to the finite element number in the discretization mesh, they are plotted as a function of $\left(\mathrm{N}_{\mathrm{e}}\right)$ in Fig. 7. Again Q1 gives good stability and convergence, while Q2 and Q3 fluctuate irregularly below or around the $\left(\mathrm{Q}_{\mathrm{pf} \text { max }}\right)$. From the previous results the perforated fin's heat dissipation computed according to the integration overall the fin heat transfer surface Q1 is more accurate and acceptable. So it will be adapted in the following calculation.

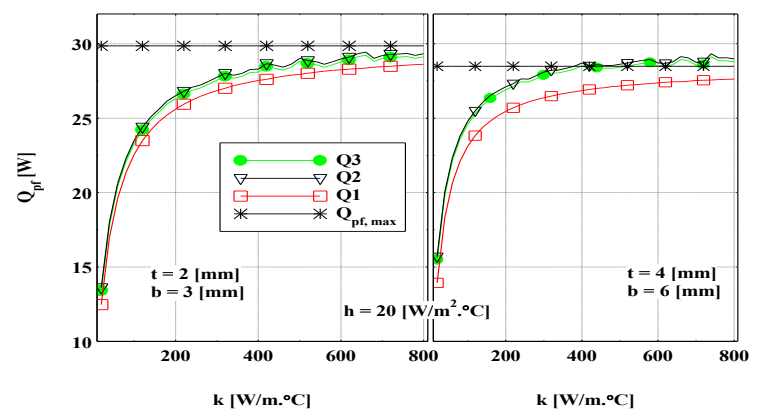

Fig.6. Heat dissipation rate of the perforated fin as a function of its thermal conductivity for various hexagonal perforation dimensions $(\mathrm{S} \mathrm{x}=\mathrm{Sy}=1 \mathrm{~mm})$..

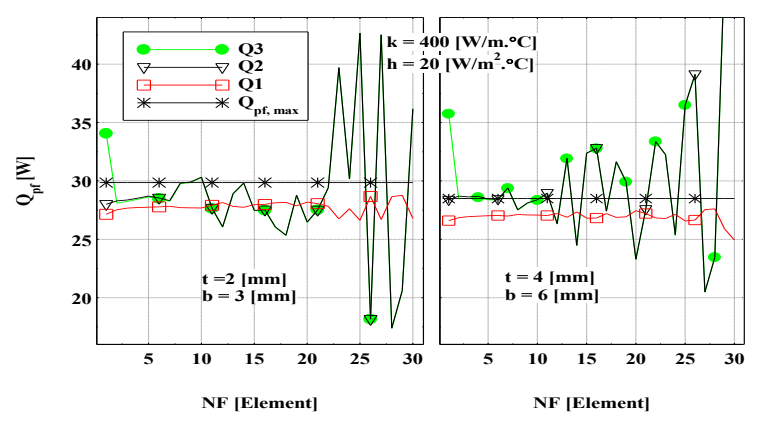

Fig.7. Fin dissipation rate as a function of the finite element number of the uniform part of the perforated fin (regions of type A or D), (Sx $=\mathrm{Sy}=1 \mathrm{~mm})$. 


\subsection{Verification OF THE HEAT Dissipation RATe OF THE PERforated Fin (Q1)}

For more verification of $\mathrm{Q} 1$, the difference $\left(\mathrm{Q}_{\mathrm{pf} \text { max }}-\mathrm{Q} 1\right)$ as a function of fin thermal conductivity for various fin thicknesses and perforation dimensions is plotted in Fig. 8. The theoretical knowledge of the fin analysis implies a positive difference of $\left(\mathrm{Q}_{\mathrm{pf} \text { max }}-\mathrm{Q} 1\right)$ and it converges to zero as the fin thermal conductivity approaches very high values. The results in Fig. 8 are consistent with the theoretical knowledge mentioned above. To compare the perforated fin heat dissipation rate with that of the solid one, RQF is plotted as a function of perforation dimension as shown in Fig. 9. It is theoretically expected that $\mathrm{RQF}$ should converge to $(\mathrm{RQF}=1)$ as the perforation dimension approaches very small values. This situation is easily observed in Fig. 9. From Fig. 9 it can be deduced that the perforations for certain dimensions lead to heat transfer enhancement. This means that the use of perforation with certain dimensions leads to heat transfer enhancement, while the other values lead to heat transfer retardation.

\subsection{Perforated Fin EFFicienCy $\eta_{\mathrm{PF}}$}

The perforated fin efficiency according to the value of (Q1) is plotted in figure 10. The efficiency has uniform curves with very small wiggles that converge to $100 \%$ as the fin's thermal conductivity approaches very high values. This result seems correct and acceptable.

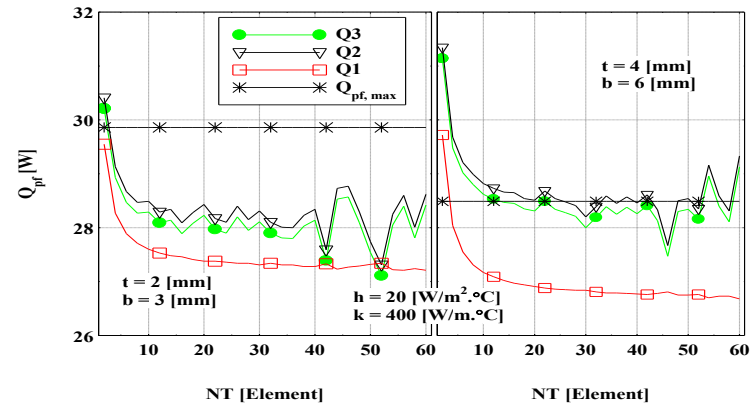

Fig.8. Fin dissipation rate as a function of the finite element number of the non-uniform part of the perforated fin (region of type B or C), $(\mathrm{S} x=\mathrm{Sy}=1 \mathrm{~mm})$..

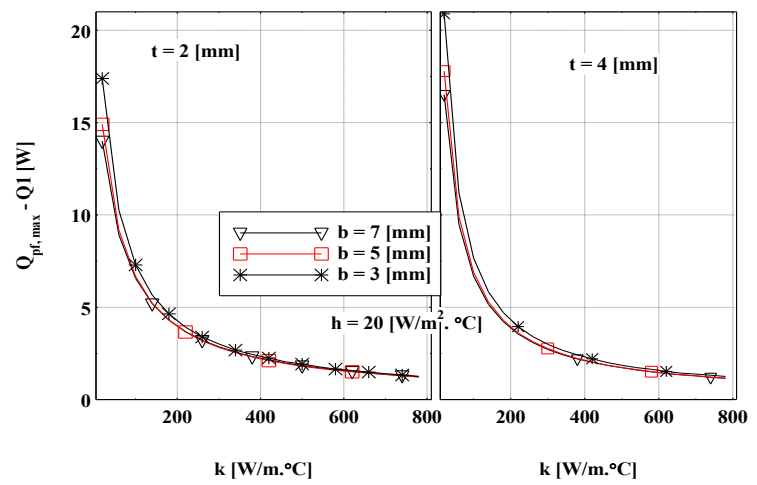

Fig.9. Fin dissipation rate difference between the maximum value and the actual one of the perforated fin as a function of the thermal conductivity $(S \mathrm{x}=\mathrm{Sy}=1 \mathrm{~mm})$..

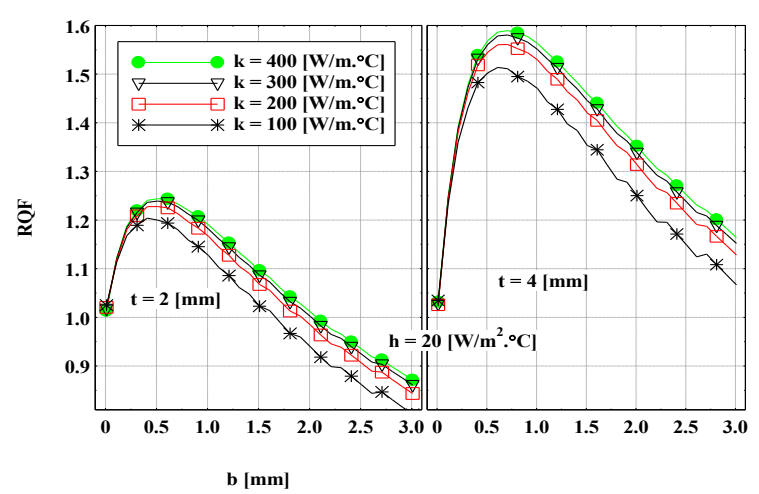

Fig.9. Heat dissipation ratio of the perforated fin to that of the non perforated one as a function of the hexagonal perforation dimension $(\mathrm{S} \mathrm{x}=\mathrm{Sy}=1 \mathrm{~mm})$.

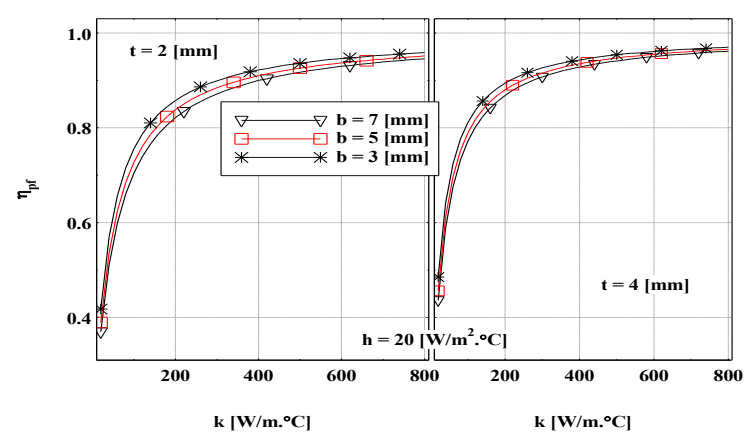

Fig.10. Perforated fin efficiency as a function of its thermal conductivity for various fin thicknesses and hexagonal perforation dimensions $(\mathrm{S} x=\mathrm{Sy}=1 \mathrm{~mm})$.

\section{CONCLUSION}

1- The one-dimensional heat transfer solution of the perforated fin leads to acceptable results as the Biot Number in lateral and longitudinal directions less than 0.01 .

2- The geometric modification made by perforation improves the performance of the fin for certain perforation dimensions. 
3- The effect of thermal conduction resistance of the fin due to perforation can be decreased by increasing the fin thermal conductivity.

\section{NOMENCLATURE}

A: cross sectional area of the solid fin [m2]

: cross sectional area of the hexagonal perforation [m2]

: cross sectional area of the finite element [m2]

: area of the inner surface of the perforation [m2]

: area of the perforated surface of the fin [m2]

b: hexagonal perforation dimension $[\mathrm{m}]$

h: heat transfer coefficient [W/m2.o C]

: heat transfer coefficient of the inner surface of the perforation $[\mathrm{W} / \mathrm{m} 2.0 \mathrm{C}]$

: heat transfer coefficient of the perforated surface of the fin [W/m2.o C]

: heat transfer coefficient of surface of the two sides of the fin [W/m2.o C]

: heat transfer coefficient of the fin tip [W/m2.o C]

k: thermal conductivity of fin material $[\mathrm{W} / \mathrm{m} . \mathrm{o} \mathrm{C}]$

$\mathrm{L}$ : fin length $[\mathrm{m}]$

l: vector unit $[\mathrm{m}]$

Le: finite element length $[\mathrm{m}]$

$\mathrm{N}$ : number of perforations

P: fin perimeter $[\mathrm{m}]$

Pe: finite element perimeter $[\mathrm{m}]$

Q: fin heat dissipation rate [W]

RQF: ratio of heat dissipation rate of perforated fin to that of non-perforated (solid) one

$S$ : perforation spacing $[\mathrm{m}]$

$\mathrm{t}$ : fin thickness [m]

Ve: finite element volume [m3]

W: fin width $[\mathrm{m}]$

Subscripts and superscripts

b: fin base

e: finite element

max: maximum

pf: perforated fin

pc: inner surface of the perforation (lining surface of the perforation)

ps: perforated surface which is the remaining solid portion of the perforated fin

s: solid surfaces of the fin sides

sf: solid (non-perforated) fin

t: fin tip

$\mathrm{x}$ : in or along the direction of $\mathrm{x}$-axis

$y:$ in or along the direction of $y$-axis

$z$ : in or along the direction of z-axis

: ambient

\section{REFERENCES}

[1] A. E. Bergles, Technique to augment heat transfer. In Handbook of heat transfer Applications, (Edited by Werren M. Rohsenow, James P. Hartnett, and Ejup N. Ganic), Ch. 3, Second
Edition, McGraw-Hill Book company, New York, 1985.

[2] R. K. Shah, Classification of heat exchangers. In Heat Exchangers, Thermal-Hydraulic Fundamentals and Design (Edited by S. Kakac, A. Bergles and F. Mayinger ), Hemisphere Publishing, NY, 1981

[3] R. Mullisen and R. Loehrke, A study of flow mechanisms responsible for heat transfer enhancement in interrupted-plate heat exchangers, Journal of Heat Transfer (Transactions of the ASME) 108, 377-385, 1986

[4] B. V. S. S. S. Prasad, A. V. S. S. K. S. Gupta, "Note on the performance of an optimal straight rectangular fin with a semicircular cut at the tip", Heat transfer engineering Vol. 14, No. 1, 1998

[5] Al-Essa, A.H., "Enhancement of thermal performance of fins subjected to natural convection through body perforation". Ph.D. thesis, Department of Mechanical Engineering, University of Baghdad, Iraq and Jordan University of Science and Technology, 2000

[6] E. M. Sparrow and M. Carranco Oritz, "Heat transfer coefficient for the upstream face of a perforated plate positioned normal to an oncoming flow", Int. J. Heat Mass Transfer. Vol. 25,No. 1, PP $127-135,1982$

[7] Al-Essa, A.H., Al-Hussien, F. M.S., "The effect of orientation of square perforations on the heat transfer enhancement from a fin subjected to natural convection", Heat and mass transfer 40 509-515, 2004

[8] C. F. Kutscher, Heat exchange effectiveness and pressure drop for air flow through perforated plates with and without crosswind, Journal of Heat transfer 116, 391-399, May 1994

[9] Wadhah Hussein Abdul Razzaq Al- Doori, Enhancement of natural convection heat transfer from rectangular fins by circular perforations, International Journal of Automotive and Mechanical Engineering (IJAME), Volume 4, pp. 428-436, July-December 2011.

[10] M.R. Shaeri, M. Yaghoubi, K. Jafarpur, Heat transfer analysis of lateral perforated fin heat sinks, Applied Energy 86 (2009) 2019-2029

[11] P. Razelos and E. Georgiou , "Two Dimensional effects and design criteria for convective extended surfaces", heat transfer engineering Vol. 13, No. 3, p 38-48, 1992 
[12] A. Aziz and V. Lunadini, Multidimensional steady conduction in convicting, radiating, and convicting-radiating fins and fin assemblies, Heat Transfer Engineering 16(3), 32-64, 1995

[13] Rao, S. S., "The Finite Element Method in Engineering", Second Edition, Elmsford, NY: Pergamon, 1989.

[14] Abdullah H. M. Al-Essa, "One Dimensional Finite Element Solution of the Rectangular Fin with Rectangular Perforations", WSEAS TRANSACTIONS on HEAT AND MASS TRANSFER, Issue 10, Volume 1, P 762-768, October 2006

[15] Abdullah H. M. AlEssa, "One-dimensional finite element heat transfer solution of a fin with triangular perforations of bases parallel and towered its base", Archive of Applied Mechanics, Springer-Verlag, Volume 79, Issue 8, , Pages 741751, August 2009

[16] 16. Frank P. Incropera and David P. Dewitt, Fundamentals of Heat and Mass Transfer (Forth Edition),John Wiley and sons, New York, 1996 


\section{تحليل تبديد الحرارة من زعنفة بها ثقوب سداسية من جاتب واحد وموازية لقاعدتها \\ عبداله العيسى \\ قسم الهندسة الميكانيكية، كلية هندسة عرعر، جامعة الحدود الثمالية، المملكة العربية السعودية}

الملخص:

تعتبر طريقة العناصر المنتهية من الطرق الهامة في دراسة و تحليل مسائل الهندة الحرارية. عادة يتم تقسم العناصر المدروسة إلى عناصر جزئية منتظمة منتهية الصغر للحصول على توزع درجات الحرارة في الزعنفة أو الصفيحة. في هذه الورقة يتم دراسة عددية لتبديد الحرارة بالانتقال الحراري من زعنفة أفقية مستطيلة محفور بها ثقوب سداسية راسية و ذلك باستعمال طريقة العناصر المنتهية أحادية البعد. توجيه التقب السداسي يأتي بحيث أن اثنين من جو انبه الستة توازي قاعدة و نهاية الزعنفة. جسم الزعنفة ينم تقسيمه إلى العدد الكافي من العناصر المنتهية. عدد هذه العناصر يمكن تغييره و حسب الحاجة بموجب توليد أتوماتيكي لثبكة العناصر المنتهية. التبديد الحراري من الزعنفة المثقبة يحسب و يقارن مع مثيلة للزعنة الصلبة غير المثقبة ذات نفس الأبعاد و الخواص الحرارية. المقارنة تشير إلى نتائج مقبولة من حيث تدعيم تبديد الحرارة عند مو اصفات محددة للثقوب. 